Revista de Filosofía

Volumen 71 (2015) 65-78

\title{
ALGUNAS ARISTAS DE LO QUE ESTÁ EN JUEGO EN LA POLÍTICA DE LA ESTÉTICA EN JACQUES RANCIÈRE ${ }^{1}$
}

\author{
Emilse Galvis \\ Universidad de los Andes, Bogotá, Colombia \\ emilse_galvis@hotmail.es
}

No es la revuelta del trabajador explotado sino la cólera del pensamiento abandonado lo que viene a frenar los movimientos del cuerpo afirmando su derecho. Pero este derecho de un alma, a la que el encierro del taller no deja percibir, por la elevada ventana, otra libertad que el vuelo de los pájaros o el movimiento de las hojas, se encuentra al mismo tiempo repuesto: deviene el sueño de una vida vegetativa que aboliese el dolor o de una vida animal cuyo libre vuelo esté hecho del olvido de sí.

Rancière, Jacques. La noche de los proletarios

recuerdo de su mirada atenta y dulce, de su bella mano llena y triste cuando pintaba; un arsenal bonito, desorden de los regalos de los fieles que siguió por doquier a la dueña de la casa y que acabó por adquirir la marca y la fijeza de un rasgo de carácter.

Proust Marcel. En busca del tiempo perdido

Resumen / Abstract

Este artículo sugiere algunas aristas que permiten pensar lo que está en juego en la política de la estética en la filosofía de Jacques Rancière. A partir de una de las escenas de la obra Aisthesis, el texto pretende enlazar dos registros de la política de la estética: por un lado, la irrupción del régimen estético del arte como un tejido de la experiencia sensible que desestabiliza las determinaciones de lo que quiere decir el "universal reportaje"; y por el otro, ciertas formas de emancipación singular que se ponen en escena en experiencias éticas de des-identificación que irrumpen en el orden consensual.

1 Este texto forma parte del proyecto ECOS-Nord/COLCIENCIAS “Comprender la subjetivación política hoy: experiencias y conceptualizaciones (Colombia-Francia)" del Departamento de Filosofía de la Universidad de los Andes. 
Palabras Clave: Jacques Rancière, estética, política, ética, Kant, policía, brecha, subjetivación.

\section{SOME EDGES ABOUT THE ESTHETICS POLICY TO JACQUES RANCIÈRE}

This article suggests some edges that allows to think about the esthetics policy according to Jacques Ranciere philosophy. From one of the Aisthesis scenes, the text pretends to join two esthetics policy records. In one hand, the incursion of the esthetic regime of arts as a tissue of sensitive experience that destabilizes the conclusions of the meaning of "universal reportage"; on the other hand, certain forms of singular emancipation which are showed in ethic experiences of un-identification that broke the agreed order.

KEY WORDS: Jacques Rancière, esthetics, policy, ethics, Kant, police, gap, subjectivation.

\section{Introducción}

R⿴囗十

Una de las nociones más sugerentes para intentar esclarecer algunas aristas

de lo que está en juego en la política de la estética es la de distancia (Écart) o brecha como la emplearemos en este texto. Brecha no entendida como una suerte de resquicio por donde algo empieza a perder su entereza o como una mera ruptura, sino como aquella forma de figuración disensual de la experiencia sensible en la que se (des)dibujan cuerpos, miradas, distribuciones e individualidades y en la que se crean, a su vez, paisajes inéditos de lo visible y formas nuevas de habitación de lo común. La política de la estética se manifiesta así en distancias, en brechas o en escenas de disenso que figuran nuevas formas de exposición de lo visible y nuevas formas de producción de los afectos que posibilitan la irrupción de capacidades inéditas en el orden de lo sensible dado. Recordemos que en la conferencia titulada La política de la estética ${ }^{2}$, presentada por Rancière en el año 2003, el filósofo afirma que el arte "es político en tanto que sus haceres moldean formas de visibilidad que reenmarcan el entretejido de prácticas, maneras de hacer y modos de sentir y decir en un sentido común; lo que significa un "sentido común" encarnado en un sensorium común" (Rancière 2006). Es decir, que hay una política de la estética en el sentido en el que su figuración posibilita nuevas formas de circulación y exposición de lo visible. Describiremos a continuación una escena, una y muchas escenas a la vez, que será el horizonte de partida para lo que queremos proponer en este recorrido:

En la escena número 14 de Aisthesis (2013) titulada "El resplendor cruel de lo que es" ${ }^{3}$ se da cuenta de un minucioso inventario de los objetos de tres familias de Alabama que inicialmente tendría la intención de aparecer con su "respectiva

2 Presentada por Rancière en el año 2003 y publicada en 2006 por la revista Otra parte. Recurso electrónico http://www.revistaotraparte.com 1936 Nueva York, "Condado de Hale". 
fotografía" en la revista Fortune, especializada en grandes reportajes periodísticos. Tanto la imagen como el texto, en aquella ocasión, debían dar cuenta de la manera cómo viven los tiempos de la crisis y el New Deal individuos y familias representativos de la Norteamérica pobre. El objetivo era claro: dar cuenta de un sector social al que se sabe particularmente miserable y de las maneras de vivir del norte industrial, esto es, de las formas de vida de un obrero de la construcción o de un aparcero que trabaja en los algodonales del sur. Para cumplir tal propósito, la revista envía al joven James Agee, quien en compañía de su amigo Walker Evans deciden que, a diferencia de lo que espera el "universal reportaje", cada uno trabajará por su lado, texto y fotos serán independientes y "[d]e hecho ninguna foto mostrará al lector las resquebrajaduras del secreter o la familia de perros de porcelana. Ninguna leyenda acompañará las fotos. Y ningún texto del reportero nos explicará las circunstancias en que el fotógrafo ha reunido a tales o cuales miembros de una de las tres familias" (Rancière 2013, p. 286).

El resultado de este trabajo, a partir de la decisión de Agee y Evans, no fue un artículo sobre los campesinos algodoneros del sur de los Estados Unidos y tampoco se publicó en ninguna revista; el resultado del trabajo se publicó en forma de libro bajo el título Elogiemos ahora a hombres famosos ${ }^{4}$, texto que tuvo alrededor de 500 páginas. El relato, en este caso, más allá de narrar la vida de la esposa, de los hijos y la vida misma del agricultor se dedica a detallar cada cosa, cada olor, cada hendidura de los objetos resultado del azar o del ambiente en la forma de una minuciosa descripción. Así, en la vivienda del agricultor se señalan los muebles cubiertos de telas, las fotos de los niños sobre el piano, las estanterías acristaladas donde viejos libros escolares se codean con obras religiosas. Así, en uno de los inventarios dice lo siguiente:

El secreter fue en una época un mueble absolutamente pequeñoburgués. Es muy grande y pesado y está enchapado de una madera de color rojo oscuro y rica textura; tiene placas de metal diestramente cinceladas en los tiradores de los tres cajones; el espejo, de al menos tres pies de alto, está rodeado de un marco de madera esculpido a máquina. El enchapado está ahora agrietado y en varios lugares se ha despegado de la base de madera blanda amarilla. Casi todos los tiradores de los tres cajones están descuajeringados y dos de ellos han desaparecido. Abrir y cerrar los cajones es toda una historia. El espejo está deteriorado a tal punto que lo irisan láminas grisáceas y, en todo lo que refleja, una superficie de platina galvanizada de insondable tristeza da a su marco la belleza casi inmemorial, suave, frágil y lamentable que hacen ver los ferrotipos de retratos de familia en un desorden de

4 James Agee y Walker Evans dan voz a las familias más afectadas por la Gran Depresión de los años treinta en Estados Unidos. Convivieron durante los meses de julio y agosto de 1936 con tres familias de campesinos algodoneros del sur de Estados Unidos. El resultado de esta perturbadora experiencia es uno de los libros más originales y a la vez influyentes del siglo XX: un auténtico canto a la dignidad humana, una obra atemporal que enaltece a todas aquellas personas anónimas víctimas del capitalismo más atroz. En Agee J. Y Evans W., Elogiemos ahora a hombres famosos. Planeta, 2008 
estudio, o que hacen oír los discos de jazz prontos a exhalar el último suspiro [... ] (Rancière 2013, p. 283).

Ante tal descripción, se pregunta Rancière, “¿A qué género de literatura pertenecen estos minuciosos inventarios que parecerían trasponer al decorado de la vida pobre la descripción balzaciana de los interiores burgueses de provincia, si no se mezclara con ellos una mirada soñadora siempre presta a inmovilizarse en alguna incongruencia surrealista: botón roto, muñeca mutilada, montaje de recortes o aguja decorada con un cisne?" (Rancière 2013, p. 285).

En este artículo quisiera proponer que en esta escena del "resplendor cruel de lo que es" se pueden hilar por lo menos dos registros de la política de la estética: Un primer registro tiene que ver con el régimen estético del arte, esto es, con la irrupción de aisthesis, entendida como una forma de ser y no solo de hacer (poiesis) que desestabiliza la percepción de lo que significa arte en tanto se configura como un tejido de la experiencia sensible que se manifiesta en ciertas escenas y acontecimientos muy prosaicos que pudieron resignificar lo que fue asumido como arte en el momento propio del régimen estético. Es decir, un registro de la política del arte que, en oposición a una forma de arte representativo ${ }^{5}$, se habría encargado de desdibujar las fronteras entre arte y vida, entre razón y sensibilidad, entre arte y no arte y entre aquellos que son considerados como seres partícipes (esthesis) en el reino del lenguaje y aquellos que se manifiestan como poseedores de una palabra (hexis). Un segundo registro de la política de la estética que se pone de manifiesto en esta escena es aquel que reúne ciertas experiencias éticas de desidentificación ${ }^{6}$ o aquellos movimientos de los obreros o reporteros sobre sí mismos que permiten desplazar ciertas fronteras en sus modos de ser, en sus modos de ver y de existir. Este registro se podría comprender mejor en aquella figuración de algunos personajes de La noche de los proletarios (2010) que expresan una forma de emancipación singular a partir de ciertos movimientos que no son causados por una orden de su patrón sino por su propia voluntad. Así pues, por ejemplo, aquel modo de vivir experimentado por Gauny se mueve entre la identidad del carpintero pero también del poeta-escritor de modo que su propia existencia manifiesta un acto en el que se pone en cuestión la separación entre los usos de la palabra y las consecuencias que trae consigo la ordenación de las jerarquías sociales fijadas por un orden social y consensual.

A la luz de estos dos registros, tanto del régimen estético como de algunos actos de emancipación que se manifiestan en experiencias éticas de desidentificación, quisiera

5 Para Rancière, este régimen representativo de las artes, a partir de Aristóteles, se habría encargado de fijar ciertos cánones y modos de percepción en las obras de arte que adquirían ciertos rasgos de una comunidad unívoca a partir de categorías como proporción, belleza, expresividad.

6 Experiencia ética entendida a partir de ciertas prácticas de desidentificación que suponen franquear los límites impuestos por una forma de conducta para repensar y habitar nuevos modos de existencia. 
leer esta escena disensual del "Resplendor cruel de lo que es": por un lado, en cuanto a la irrupción de la aisthesis, se suspende aquella adecuación y plena correspondencia entre la imagen y el texto que presuponen los toscos inventarios del "universal reportaje". Para éste, el periodista es el encargado de elegir los signos necesarios para mostrar "toda" la miseria de estas familias algodoneras del sur. No obstante, este registro estético del arte se entrelaza con las formas de vida particulares de estos periodistas que rompen con las labores asignadas propias de su trabajo. Es decir que en el momento en el que James Agee y Walker Evans deciden suspender la lógica consensual del "Universal reportaje" ya no seguirían siendo los mismos periodistas y su identidad se habría trasladado, o quizás multiplicado, entre una forma de vida particular de algodonero, poeta, periodista o escritor. Entonces, ¿cómo pensar esta resignificación en las vidas de estos "reporteros"? ¿En qué sentido estas pequeñas desidentificaciones darían cuenta de una cierta experiencia ética de subjetivación tal y como la entiende Foucault?, y ¿cómo entender estas experiencias a la luz de ciertas formas de emancipación que se ponen de manifiesto en La noche de los proletarios? En este texto trataremos de dar cuenta de la manera cómo los dos registros de la estética que hemos mencionado se entrelazan en esta escena particular: a la vez que estas narraciones vivas manifiestan una suspensión de los cánones de adecuación entre parte y todo, entre imagen y texto, entre realidad y ficción; James Agee y Walker Evans a la vez transforman sus modos de existencia y experimentan desplazamientos en sus modos de ser, de hablar y de sentir. Vayamos despacio para tratar de desenmarañar lo que hasta aquí está expuesto.

\section{Del gesto pensante a la palabra sensible: Un minucioso inventario, un} nuevo régimen del arte

En principio diremos que estas descripciones exhaustivas de madera, muebles, objetos, decoraciones murales; estas frases interminables que dan cuenta de los cajones del secreter, del inventario estante de la chimenea, etc. de estas tres familias de Alabama responderían inicialmente a un reportaje periodístico de la revista Fortune que, como ya mencionamos, se inscribe en una serie destinada a mostrar cómo viven los tiempos de crisis individuos y familias representativos de la Norteamérica pobre. El joven James Agee debe ocuparse de "los efectos de la crisis sobre un sector al que se sabe particularmente miserable sin poder imaginar esa miseria" (Rancière 2013, p. 286). ¿Qué significa esta afirmación de "no poder imaginar esa miseria"? En efecto, no se la podría imaginar porque el "Universal reportaje" ya habría establecido el efecto de este artículo periodístico y ya sabe cuál es esa miseria de aquellos obreros de la construcción, de los aparceros de Alabama y de sus familias.

En primera instancia diremos que la "universalidad" de estos reportajes se dice entre comillas porque desde siempre se ha guardado de decirlo y fotografiarlo todo, para este grupo de seres humanos llamado revista ese "todo", nos dice Rancière, no es más que una "doxa perezosa sostenida por los nostálgicos de las bellas letras y las bellas artes de antaño, y luego recuperada por los campeones de cierto modernismo 
(que) opone la cuidadosa selección de los elementos del arte a los toscos inventarios del "reportaje universal" (Rancière 2013, p. 286). Su universalidad consiste en una correspondencia entre hechos e ideas y por supuesto entre ideas e imágenes que ya se saben de antemano y que deben corresponder a la "realidad". El periodista debe elegir así los signos que basten para reflejar la miseria y, la comunicará sin más a un público que la reconocerá. Si es tal la predeterminación, este tipo de reportaje periodístico se suscribe, sin lugar a dudas, en un régimen representativo del arte que presupone los efectos de la fotografía e intenta interpretar tales hechos ${ }^{7}$. Estas adecuaciones entre texto e imagen, entre el trabajo de los periodistas y los hechos determinan aquello que define a un objeto como arte en el sentido propio del régimen representativo: unas categorías fijas y establecidas que definen a los objetos y a sus productores en o afuera del mundo de las artes. Así, el fotorreportaje se rige por ciertos cánones de efectividad que contienen el doble exceso en el cual podría perderse tal arte, por un lado, i) una falta de concordancia entre palabras e imágenes; y por otro lado, ii) el exceso de signos tan triviales que ya no habría razón para elegir unos u otros.

El "universal reportaje" se encargará entonces de reproducir aquella relación armónica y unívoca promovida por las bellas artes y las bellas letras en la tradicional definición de la mímesis. Esta definición presuponía una relación ya establecida y reglamentada entre las formas de hacer (poiesis) y una cierta forma de ser (aisthesis). En este sentido, el régimen representativo de las artes siempre habría estado involucrado de cierta manera con un régimen policial, esto es, con una cierta actividad o una forma particular de simbolizar lo común que organiza la reunión de los hombres en la comunidad sobre la base de una suerte de consenso y que consiste básicamente en la distribución jerárquica de lugares y funciones que se constituyen en el "ser" de esos individuos. La policía, no entendida como una forma de represión y control social sino con una actividad que toma parte en lo común, que organiza la reunión de los seres humanos en una comunidad y que a su vez ordena y toma partido en la sociedad en términos de funciones, de lugares y títulos que deben ocuparse. En términos del filósofo francés, "el principio de la "policía" siempre ha consistido en partir a la humanidad entre los que "saben" y esos de los que se dice que simplemente manifiestan descontento, furor, histeria" (Rancière 2010 p. 74). Aunque no haremos referencia a este principio, en el fondo Rancière parece estar apuntando a que la policía ha estado involucrada con uno de los problemas centrales de la filosofía política desde la Antigüedad, que consiste en la definición de lo común y en la distribución de roles, lugares y de la palabra misma que distribuye a los individuos según su actividad. De este modo, el "Universal reportaje" reproduciría aquella pretensión de una comunidad consensual en la que las artes

7 Lo que define a un objeto como arte, según el régimen representativo, son unos criterios específicos que definen a los objetos y a sus productores en o afuera del mundo de las artes. Aquellas normas de pertenencia, de acuerdo con la poética aristotélica, se regían por los cánones que fijaban unos modos de proporción que hacían coincidir el todo con sus partes, y una expresividad en donde las obras de arte adquirían rasgos de comunicabilidad unívocos (Rancière 2012, p. 20). 
liberales estaban separadas de las artes mecánicas en tanto estas últimas eran solamente pasatiempos de hombres libres, "hombres de ocio a quienes su calidad misma debía apartar de la búsqueda de una perfección excesiva en realizaciones materiales de las que podían encargarse un artesano o un esclavo" (Rancière 2013, p. 9).

Ante estas determinaciones del régimen de la representación y del orden policial, Rancière señala que el arte comenzaría a existir en Occidente justamente cuando estas formas de vida empezarían a vacilar ${ }^{8}$. En este sentido, Rancière se habría encargado de señalar que la aisthesis (estética) no se deduce de un concepto general de lo que quiere decir arte o belleza de acuerdo con un concepto global de justicia, la aisthesis designa un modo de experiencia sensible que habría transitado algunos desplazamientos con respecto a la percepción de lo que quiere decir "arte" y se habría ocupado de desdibujar las fronteras entre arte y vida. En la escena que nos ocupa, al contrario de lo que esperaba la revista Fortune, la decisión que tomaron James Agee y su amigo Walker Evans lo que hizo fue justamente explotar ese doble exceso del "universal reportaje" que se ajustaba a un anhelo de correspondencia entre texto e imagen y a la eficaz decisión del reportero de elegir unos signos precisos que dieran cuenta de la pobreza. A diferencia de esta adecuación, la decisión de decirlo todo literalmente, de no excluir de los inventarios ningún objeto, ningún detalle, ningún color u olor, lo que provocó fue la suspensión absoluta de toda determinación. Así, "[1]a decisión de decirlo todo no es en modo alguno la consumación de la lógica periodística. Al contrario, la hace estallar y, con ella, cierta lógica del arte" (Rancière 2013, p. 288). El detalle frívolo de cada objeto de estas familias y estos largos inventarios de camisetas, alfileres, machas, ojales de alpargatas, calcetines, guantes, suspenden la pretendida reseña de la situación de los campesinos pobres de la sociedad, suspenden el régimen representativo del arte y con esta suspensión crean una brecha en aquella pretendida comunidad consensual que se atribuye el derecho a curiosear en la vida de los pobres. El inventario excede cualquier adecuación de estas familias, porque nunca la descripción de un hogar será igual a las otras y la incesante descripción llevada casi hasta el infinito no podría responder a la pregunta de ¿cómo viven la crisis los constructores y algodoneros del sur?

8 Así pues, la política no es una mera lucha por el poder, ni una búsqueda incesante por la repartición de los bienes de la sociedad, pero tampoco se trata de decir, en un sentido aristotélico, que los seres humanos son políticos en tanto poseen el poder del habla (logos) mientras que los animales solo tienen voz para expresar placer y dolor (phoné). Esta última comprensión daría cuenta de una cierta "política" que se pone en escena en tanto discusión pública sobre cuestiones de justicia entre personas hablantes que son capaces de hacerlo. Sin embargo, para Rancière lo anterior resulta problemático porque ¿quién tiene el poder de decidir sobre esta capacidad del habla en la escena política? Esto se enlaza además con una célebre sentencia de Platón según la cual los artesanos no tienen tiempo y no pueden ocuparse de otra cosa que no sea su trabajo, y ante esto afirma el filósofo: "Parece obvio que esta "falta de tiempo" no es del orden empírico: es la mera naturalización de una separación simbólica" (Rancière 2006). 
Esta brecha que abre el régimen estético del arte en lo que se ha llamado el "universal reportaje" y en general en los ejercicios periodísticos que se toman la atribución de hablar por aquellos que se dicen incapaces, se expresa ya no como un gesto pensante como en aquella interpretación de Winckelmann del torso desmembrado de un presunto Hércules al que se le atribuyó la ruptura frente a los cánones de la proporción y la expresividad de acuerdo al régimen representativo ${ }^{9}$, tampoco es una mirada que expresa una extrañeza como la heroína de Europa 51 o la suspensión de toda expresión en los rostros de los protagonistas de las películas de Pedro Costa. El inventario es una suerte de palabra sensible o, podríamos decir, de narración viva de la cotidianidad de las familias de Alabama que expresa una belleza singular, indeterminada pero singular. De modo que no estamos situados ante cualquier narración, es un exceso de la narración ya que ante el inventario desmesurado el lector (o el escritor) no puede más que encontrarse en un estado de juego que es tan importante para Kant en su comprensión del libre juego de las facultades y en esta idea de Schiller de pensar la experiencia estética. En Kant, en principio, supone la no determinación de la imaginación por el concepto del entendimiento y esto significa la suspensión de ese privilegio del entendimiento con respecto a la imaginación y la suspensión frente a lo sensible; y en Schiller, que se apropia de los planteamientos kantianos, se radicalizaría eso mucho más porque allí el instinto de juego tiene que ver con el entrelazamiento en el juego del entendimiento y la sensibilidad o, podría decirse, que el objeto de lo bello no es asimilable ni al entendimiento ni a la sensibilidad, atendiendo solamente a uno u otro. Tales descripciones minuciosas no son simplemente reflexiones de semanas completas de habitación y comunidad con los algodoneros del sur, de lo que se trata es de la manera cómo esa materialidad y esas formas de vida se escenifican en cada detalle narrado y de la manera cómo estos objetos en su particularidad resignifican un arte de vivir, son descripciones de objetos sensibles que adquieren vivacidad en la infinitud del inventario, las palabras no están separadas de los objetos, y tampoco los objetos de las formas de vida de estos aparceros del sur; justamente en los inventarios se pone en evidencia que no hay una dicotomía entre materialidad y reflexión. Esto, además, porque de alguna manera las palabras mismas se pueden ver como un aporte a la materialidad, y porque hay sensibilidad también en la narración (el pensamiento es gestual, la palabra es material). Dejemos ahí este primer registro de la política de la estética.

9 Las palabras de Winckelmann con las que Rancière inicia el primer capítulo de Aisthesis son sumamente esclarecedoras, pues en una tradición en la que las figuras incompletas no eran aprehensibles, la escena que crea el historiador del arte alemán muestra la belleza de una representación incompleta del cuerpo y la actividad humana. El esplendor de la belleza antigua escenificado por un torso mutilado pone en entredicho los cánones de las bellas artes que reglaban las formas de expresividad de las obras y los contornos de la proporción. Este llamado al quiebre de la belleza reglada del régimen representativo de las artes es la puesta en marcha de una escenificación que crea la comunidad sensible para la cual este, un objeto cualquiera, es susceptible de hacer parte del arte (Rancière 2013). 
II. Una nueva subjetividad: Agee y Evans, ¿quién se atribuye el derecho a meterse a curiosear en la pobreza?

En "Las paradojas del arte político"10, Rancière, hablando de la Juno Ludovisi de Schiller, del torso desmembrado de Belvedere y del llamado de Rilke en el Louvre, trae a colación lo que él llama "otra historia de miembros y de mirada que transcurre en otro escenario" (Rancière 2010, p. 63). Con estas palabras, el autor introduce la siguiente experiencia: En el periodo de la revolución francesa, el diario revolucionario obrero publica la descripción de la jornada de trabajo de un obrero carpintero ocupado de entarimar una habitación por cuenta de su patrón y del dueño del lugar; lo que rescata Rancière de esta descripción, que es también el punto que queremos señalar, es "una disyunción entre la actividad de los brazos y de la mirada que sustrae al carpintero a esta doble dependencia" (Rancière 2010, p. 63). Así el proletario Gauny,

[c]reyéndose en casa, mientras no ha terminado la habitación que está entarimando, aprecia la disposición del lugar; si la ventana da a un jardín o domina un horizonte pintoresco, por un momento detiene sus brazos y planea mentalmente hacia la espaciosa perspectiva para gozar de ella mejor que los poseedores de las habitaciones vecinas (Gauny, G. 1985, p. 45-46).

La mirada de Gauny que suspende la actividad, esa mirada que se separa de los brazos y quiebra las tareas asignadas, inserta una escena de disenso o inserta una brecha entre dos regímenes de sensorialidad: un régimen policial que distribuye jerárquicamente los lugares y funciones que se constituyen en el "ser obrero" de esos individuos; y un espacio distinto de la mirada y la imaginación de Gauny que (des)dibuja aquella afirmación según la cual "el trabajo no espera". Para este gran personaje "el trabajo sí espera" y sí lo hace porque en medio de sus haceres puede dar lugar a una posibilidad del extravío a una posibilidad de "soñar". La brecha no es, sin embargo, solo una ruptura en la división entre aquellos que están sometidos a la necesidad del trabajo y estos proletarios que disponen de la libertad de esa mirada, la brecha es también la configuración de un nuevo cuerpo que se ha desidentificado de una cierta identidad, esto es, un cuerpo que ha dejado de actuar en los límites del reparto de lo sensible dado. Aquí me surgen algunas preguntas sobre las cuales haré apenas algunas puntadas. ¿En qué sentido esta desidentificación puede comprenderse mejor a la luz de la experiencia ética de subjetivación tal y como la plantea Foucault? ¿De qué manera los reporteros neoyorkinos también experimentan una cierta desidentificación? Veamos algunas aristas que nos acerquen a estas preguntas.

Ciertamente, cuando Rancière se refiere a "otra historia" y a "otro escenario" e introduce inmediatamente la experiencia de Gauny, podríamos pensar, siguiendo nuestro recorrido, que hace tal aclaración porque de cierta manera se trata de otro registro de la política de la estética, un nuevo registro no totalmente separado del 
régimen estético del arte, pero distinto en la medida en la que hace énfasis, ya no tanto en una desidentificación de un régimen representativo del arte sino de una identidad. Expresemos mejor esta afirmación; en un sentido amplio podemos decir que en los dos registros hay una política de la estética en el sentido en el que su figuración posibilita nuevas formas de circulación y exposición de lo visible y nuevas formas de producción de los afectos que determinan capacidades inéditas que irrumpen el orden de lo sensible dado. Tal irrupción en los dos casos se enlaza con esta "idea" de juego de la que ya hablamos que permite repensar la experiencia estética ${ }^{11}$. Sin embargo, en un sentido quizá más estrecho, podríamos afirmar que la brecha que se abre en esta escena de Gauny construye una nueva corporalidad que se expresa en una experiencia ética de subjetivación, y en este sentido el énfasis de este nuevo registro de la política de la estética sería distinto porque haría énfasis en ciertas escenas disensuales de desidentificación y en ciertas prácticas de sí de los proletarios de la Francia de 1830. Desanudemos esta cuestión con la escena que nos ha ocupado desde el inicio.

En Elogiemos la vida de los hombre famosos (1993), Walker Evans afirma que su amigo Agee "trabajaba en una especie de frenesí y arrebato. En Alabama estaba poseído por la tarea y la comprimía toda en los días y las noches (...). En realidad la vida mísera y aislada del campo no le era muy ajena. La llevaba un poco en la sangre, a través de unos parientes de Tennessee. De todos modos, huía de las oficinas editoriales de las revistas neoyorkinas, de las veladas sociointelectuales" (Agee y Evans 1993, p. 8). En principio, la cita nos dice quizá algo más sobre la vida de estos reporteros que tomaron la decisión de decir completamente todo en los inventarios de su experiencia, pero que además lo hicieron en nombre de una especie de radicalismo político. Para ellos, el arte de seleccionar y fotografiar los signos de una precaria condición pertenece a "la obscena práctica por la cual un grupo de seres humanos, llamado revista, a quienes reúne en última instancia el mero incentivo del lucro, se atribuye el derecho de "meterse a curiosear en un grupo de personas sin defensa" y "hacer ostentación del estado de inferioridad, humillación, desnudez de esas vidas" (Rancière 2013, p. 288). Claramente, este "curiosear" no era el objetivo de estos amigos, en su tarea se convertirían más bien en "espías" estratégicamente inmersos en el "universal reportaje", pero muy decididos a traicionar semejante misión.

Los espías no querrían unir en estas descripciones todo con todo, sino encontrar en cada uno de los detalles el peso de la precariedad en la que habitan estas familias y el arte con el cual ellos responden a esta necesidad. De lo que se trata es de "devolver a cada elemento del inventario la dignidad de lo que él es: una respuesta a la violencia de una condición (esta es la apuesta de James Agee), una descripción que haga sensible

11 En los dos registros se ponen en marcha una cierta figuración que posibilita nuevas formas de circulación y exposición de lo visible y nuevas formas de producción de los afectos que determinan capacidades inéditas que irrumpen el orden de lo sensible dado. Además, en tanto brecha, la estética de la política, se manifiestan escenas de disenso que cuartean ciertos modos de percepción y de visibilidad que se asemejan a la experiencia estética como libre juego de las facultades tal y como la habrían pensado Kant y Schiller. 
a la vez la belleza presente en el corazón de la miseria y la miseria de no poder percibir esa belleza" (Rancière 2013, p. 292). La política de lo bello es, en este sentido, un acontecimiento sensible siempre indeterminado en el que se figura una belleza estética que obedece siempre a metamorfosis imprevisibles: la belleza que se expresa en estos inventarios, una belleza indeterminada, se moviliza entre los azares de la existencia y los azares de la vegetación (el clima y los instrumentos de la fortuna):

Ese tejido se desmenuza como la nieve; se le hacen remiendos y zurcidos; estos se desmenuzan a su vez; nuevos remiendos y zurcidos que vuelven a romperse, y remiendos y zurcidos se multiplican sobre remiendos y zurcidos, y otros sobre estos, de manera que, a la larga, en los hombros, la camisa ya no contiene virtualmente nada del tejido originario y un hombre, George Gudger, lo recuerdo bien, y centenares de otros como él, llevan a su trabajo sobre el peso de sus hombros un tejido tan complicado y frágil, y tan profundamente consagrado a la gloria del astro rey como el manto de plumas de un príncipe tolteca (Rancière 2013, p. 293).

La belleza que reposa en este pasaje es accidental, es una belleza en la que se reconoce un arte de vivir y en el que las circunstancias de estas experiencias se "tejen" entre el arte y el azar. Ante esta descripción nos dice Rancière: "La camisa hecha de pedazos añadidos unos a otros nos recuerda, a no dudar, las "paperolas" con que se teje la página proustiana (...). El manto del príncipe Tolteca es similar a la página de escritura proustiana hecha de múltiples paperolas y, a la vez, a la gelatina hecha de innumerables pedazos de la que ella nos habla" (Rancière 2013, p. 294). Una cierta inquietud que aparece en este pasaje sobre la escritura de estos inventarios y a partir de la lectura que hace Rancière allí de una escritura proustiana nos lleva a pensar en la cuestión de la ficción. El acontecimiento de lo bello, siempre indeterminado, no podría estar separado en esos inventarios de las estrategias de la ficción de los artistas que se proponen cambiar aquel reparto de lo sensible dado y aquello que ha sido determinado como lo visible y lo decible. Los artistas se encargan de hacer ver aquello que no era visto o de resignificar eso que es visto y de generar escenas de disenso en el tejido sensible de las miradas, las percepciones y los cuerpos. En palabras de Rancière: "La ficción no es la creación de un mundo imaginario opuesto al mundo real. Es el trabajo que produce disenso (...) Este trabajo cambia nuestra percepción de los acontecimientos sensibles nuestra manera de relacionarnos con sujetos, la manera en que nuestro mudo es poblado de acontecimientos y de figuras" (Rancière 2010, p. 67). Si la ficción, según esta cita, es la puesta en marcha de una escena de disenso, entonces, ¿cómo construyen estos artistas tales estrategias que producen escenas de disenso? ¿No hay una relación entre este ejercicio de la ficción y una cierta experiencia ética de desidentificación? ¿En qué sentido estas estrategias de la ficción se enlazan con una cierta "interrogación crítica por el presente", en términos de Foucault?

Primero, podríamos decir a modo de hipótesis, que el énfasis en esta experiencia ética de desidentificación que se pone en marcha en este segundo registro de la política de la estética tendría que ver con una pregunta crítica por el presente en el sentido en el que Foucault entiende la crítica; no mencionaremos acá todas las características de ese presente, pero Rancière nos da algunas pistas en relación a éste en "el resplandor cruel de 
lo que es". En el momento en el que estos amigos deciden construir una espiral poética casi interminable de la belleza de estas humildes familias, el texto ya estaba condenado a exceder un reportaje periodístico. Los inventarios resultaron ser un libro "sin pies ni cabeza" que se publicó 5 años después sin ningún éxito y sin el más mínimo ruido. Sin embargo, mientras Agee se sumergía alegremente es sus inventarios de lo bello, un escritor, Erskine Caldwell, y una fotógrafa, Margaret Bourke-White, publicaban un libro titulado "You have seen their faces"; el libro respondía a la siguiente lógica: "en tanto que el escritor los hacía hablar, la fotógrafa, provista de un control remoto, esperaba el momento oportuno para captarlos de improviso en el instante de expresividad óptima" (Rancière 2013, p. 298). Así, en las fotografías se puede ver a la madre desalojada en la carretera interurbana con sus dos chiquillas o a dos ancianas de ojos apagados, etc. El auge de la cultura del New Deal no dejó de responder al régimen representativo, y la reproducción de la pobreza no se hizo esperar en los reportajes periodísticos de la época. En su momento, los escritores, fotógrafos, y cineastas de la cultura del New Deal alcanzaron un auge apoteósico y fueron reconocidos y nombrados en The New York Times y otros periódicos. Sin embargo, James Agee se mantuvo ajeno a este proceso; fue precisamente "esa misma cultura la que, durante aquellos años, sufrió un descrédito creciente en el medio de pertenencia de Agee, el de los intelectuales y artistas radicales, y con ella, toda la tradición política y estética en cuyo marco su exceso se apartaba de la norma" (Rancière 2013, p. 299).

Lo que sale inmediatamente a la luz con este presente en el que se encontraba James Agee es una forma de desidentificación de estas identidades establecidas de lo que significó un periodista o un escritor en la cultura del New Deal. En términos de Foucault podemos decir que de lo que se trata es de un movimiento crítico del sujeto sobre sí en el que se interroga por su presente y se cuestiona las formas de conducta establecidas, esto es un franqueamiento efectivo de los límites de la acción que supone vislumbrar y transitar nuevos modos de existencia. Agee y su amigo Walker estarían franqueando los límites impuestos de lo que quiso significar ser fotógrafo, reportero o escritor, y de allí que el resultado de sus investigaciones tampoco pretenda fijar identidades de los algodoneros del sur; estos espías habrían puesto en escena lo que Foucault llama una contra-conducta y que define de la siguiente manera: "Por un lado son movimientos caracterizados por un querer ser conducido de otra manera, cuyo objetivo es, así, un tipo diferente de conducción; pero que también, por el otro lado, buscan indicar un área en la cual cada individuo puede conducirse a sí mismo, el ámbito de la conducta y el comportamiento propios" (Foucault 2011, p. 25). Tal y como lo entendemos, lo que estaría en juego en estas experiencias de desidentificación en el caso de los reporteros es una forma de contraconducta en el sentido en el que se oponen a una forma establecida del "ser" periodista en la cultura del New Deal, estos personajes transitarían así en un proceso de subjetivación en el que insistirían en decir y asumir el "no somos periodistas", "no queremos utilizar la pobreza para incrementar nuestro lucro" y "no queremos tampoco que se asuma sin más la condición desgraciada de los algodoneros del sur". 
Para ir cerrando nos quedan un par de preguntas por resolver y muchas otras que dejaremos abiertas. ¿Qué pistas nos arroja esta experiencia ética de los reporteros para pensar los desplazamientos de los personajes que aparecen en La noche de los proletarios y en qué sentido lo que mencionamos como "proceso de subjetivación" resulta clave para pensar en estas experiencias? ¿Cómo pensar el tránsito de un proceso de subjetivación ética (y política, para Foucault) a una subjetivación política tal y como la entiende Rancière?

En primera instancia, una pista que nos ha dado este recorrido consiste en que el énfasis en ciertas experiencias éticas que se pone en escena en La noche de los proletarios son experiencias que hacen parte de un proceso de subjetivación. Es decir, que la suspensión entre la actividad de los brazos y de la mirada que sustrae Gauny está acompañada de otras escenas disensuales que hacen parte de un proceso o de un camino de subjetivación ética que lo han llevado a actuar de esa manera. En el caso de Gauny, aunque podríamos también seguir el transitar de Jeanne Deroin, se trata de muchas escenas que podrían tejerse: la escritura de poesía, las reuniones de noches enteras dedicadas a la lectura, la experiencia del orden del consumo de la economía cenobítica, etc. Estas actividades que transitaba Gauny entre la identidad del poetaescritor y el carpintero, además de habitar un mundo otro del obrero y de operar bajo una lógica diferente al orden policial, se suscribían en un proceso de subjetivación o en un tejido de acontecimientos que harían emerger experiencias éticas de desidentificación. En palabras de Tassin: "La subjetivación definiría así un "extraño llegar a ser sujeto" incesantemente diferido, el devenir inacabado del sujeto (y no su acabamiento), o incluso el devenir sujeto en el no acabamiento de sí (..). En pocas palabras, la idea aquí de subjetivación es la de la producción de una disyuntura, de una des-identificación, de una salida fuera de si “(Tassin 2012, p. 37) (Énfasis mío).

Finalmente, son estas brechas o estas escenas que forman el tejido disensual las que posibilitan formas de enunciación subjetiva propias de los colectivos políticos y esto es algo que ya nos hacía saber Rancière en Las paradojas del arte político. Sin embargo, estas formas de la experiencia estética, para posibilitar la emergencia de mundos propios de un nosotros político, "deben" estar encadenadas en un proceso de subjetivación ética. Es decir, que para que se posibilite un tránsito de las formas de la experiencia estética a la subjetivación política, estas brechas o acontecimientos que irrumpen tanto en el régimen estético como en el registro de La Noche de los proletarios tendrían que estar ancladas a un proceso de subjetivación ética. Esto no significa que estemos afirmando un calculo determinable de lo que significa este tránsito porque reconocemos con Rancière que "no hay ningún principio de correspondencia determinado entre esas micro-políticas de la re-descripción de la experiencia y la constitución de colectivos políticos de enunciación" (Rancière 2010, p. 67). Sin embargo, sí consideramos que este tránsito podría ser mucho más posible si intentáramos articular estas escenas de disenso, estas distancias que (des)figuran las formas de percepción y las identidades, con procesos de subjetivación ética como los que podrían hallarse en el caso de Gauny o de Jeanne Deroin en La Noche de los proletarios , pero también como los procesos de subjetivación de estos reporteros que decidieron oponerse a una forma de identidad del ser "periodista" o "escritor". En esta escena, como vimos, las brechas que causaron 
estos minuciosos inventarios de las familias de Alabama y los retazos indefinidos de secuencias de palabras combinaban en un mismo escenario la ruptura al régimen de la representación del "universal reportaje" y las experiencias éticas de des-identificación de estos reporteros que asumieron ese "extraño ser sujeto" de un proceso de subjetivación. En la medida en la que estas nuevas formas de figuración de la estética de la política, en los dos registros que hemos seguido, hagan parte en sí mismas de procesos de subjetivación ética singulares o colectivos, quizá sea mayor la brecha que posibilitaría la emergencia de "los mundos propios de un nosotros político".

\section{Referencias bibliográficas}

Agee, J. y Evans W. (1993), Elogiemos ahora a hombres famosos. España: Seix Barral.

Schiller, F. (1990), Cartas a la educación estética del hombre. Anthropos.

Foucault, Michel (2010), Obras Esenciales. Barcelona: Paidós

(2011), Sobre la Ilustración. Madrid: Tecnos.

Rancière, Jacques (1990), "Política, policía, subjetivación", En los bordes de lo político. www.philosophia.cl / Escuela de Filosofía Universidad ARCIS.

(1996), El viraje ético de la estética y la política. Ediciones Palinodia. (2005), Sobre Políticas Estéticas. Barcelona: Universidad Autónoma. (2006), "La política de la Estética". Revista Otra parte, recurso electrónico.

(2010a), El tiempo de la igualdad: Diálogos sobre política y estética. (2010b), La noche de los proletarios. Buenos Aires: Tinta Limón. (2011), Malestar en la estética. Buenos Aires: Capital Intelectual. (2012b), La méthode de l'égalité. Paris: Bayard.

(2013), Aisthesis: Escenas del régimen estético del arte. Buenos Aires: Manatial.

Tassin Etiene (2012), “De la subjetivación política. Althusser/Rancière/Foucault/ Arendt". Revista de Estudios Sociales 43. Bogotá. 